\title{
STUDI FENOMENOLOGI RUMAH SAKIT TANPA DINDING DI RUMAH SAKIT DR MOEWARDI SURAKARTA
}

\author{
Wahyuni, Rina Sri Widayati*, Riyani Wulandari \\ Universitas Aisyiyah Surakarta, \\ *e-mail: rinadwitaruna@gmail.com
}

\begin{tabular}{ll}
\hline & Abstract \\
\cline { 2 - 3 } $\begin{array}{l}\text { Keywords: } \\
\text { Rumah sakit } \\
\text { tanpa dinding, } \\
\text { studi }\end{array}$ & $\begin{array}{l}\text { Program Rumah sakit Tanpa Dinding (RSTD) merupakan perwujudan dari } \\
\text { upaya pemerintah daerah Provinsi Jawa Tengah guna mencapai derajat } \\
\text { kesehatan masyarakat Jawa Tengah setinggi tingginya.Program kesehatan }\end{array}$ \\
& yang selama ini sudah sangat dikenal adalah upaya promotif, preventif, \\
& kuratif, dan rehabilitatif, yang kalau upaya tersebut dilaksanakan secara \\
& sinergi, saling mendukung dan optimal, niscaya permasalahan kesehatan \\
bisa diatasi dengan adekuat. Hal ini tentunya berhubungan erat dengan \\
sistem perencanaan yang selayaknya dibuat dengan merujuk pada \\
permasalahan kesehatan berdasarkan data-data yang evidence based atau \\
berbasis bukti dari berbagai elemen seperti hasil kajian/ penelitian dan \\
lain-lain, dengan harapan permasalahan kesehatan terutama yang \\
berkaitan dengan substansi RSTD dapat dilaksanakan secara adekuat. \\
Implikasinya, pemerintah yang dalam hal ini dinas kesehatan dan rumah \\
sakit perlumenyiapkan dengan baik konsep dan kebijakan seperti apayang \\
akan diimplementasikan dalam menopang berjalannya program Rumah \\
Sakit Tanpa Dinding.
\end{tabular}

\section{PENDAHULUAN}

Upaya dalam meningkatkan derajat kesehatan masyarakat seperti kesehatan Ibu dan anak (KIA), pencegahan dan penanggulangan gizi buruk dan stunting, TBC, HIV-AIDS, DBD, penyakit menular lain, dan penyakit tidak menular (penyakit jantung dan pembuluh darah, penyakit kanker, diabetes mellitus, dan penyakit kronik degeneratif lainnya), serta cakupan imunisasi, harus dilaksanakan secara komprehensif dengan melibatkan berbagai instrumen pendukung.

Program Rumah Sakit Tanpa Dinding pihak rumah sakit akan bekerjasama dengan dinas kesehatan dan puskesmas sebagai mitra untuk turun menjangkau dan melakukan kemitraan dengan masyarakat dalam memberikan program promotif dan preventif untuk pemberdayaan. Selain sosialisasi atau memberikan penyuluhan, juga untuk untuk mencari dan menemukan kasus-kasus penyakit yang dialami oleh masyarakat yang nantinya akan dicarikan solusi pemecahannya. Pihak rumah sakit bersama dinas kesehatan atau puskesmas akan melibatkan masyarakat guna menemukan orang-orang yang menderita penyakit, seperti $\mathrm{TB}$, anak yang mengalami gangguan gizi dan penyakit lainnya, sehingga hal tersebut bisa segera ditangani.

Program preventif dan promotif sebenarnya sudah dilakukan oleh dinas kesehatan, sehingga dengan dilibatkannya rumah sakit akan membuat upaya preventif dan promotif menjadi semakin kuat. Rumah sakit dilibatkan untuk bersama-sama dengan dinas kesehatan dalam upaya 
menanggulangi kasus-kasus penyakit di masyarakat agar lebih cepat ditangani.

Rumah sakit Dr Moewardi memiliki jumlah pasien yang sangat banyat, pelayanan konsep rumah sakit tanpa dinding sudah dilakukan dengan beberapa kegiatan pokok diantaranya Kegiatan Pokok,melaksanakan kegiatan promosi kesehatan seperti pengobatan gratis ,bakti sosial, di wilayah karisidenan Surakarta.Rincian kegiatan meliputiPengobatan grtais yang dilakukan setiap 2 minggu sekali, Mengadakan khitanan masal setiap 6 bulan sekali, Mengadakan kegaitan donor darah setiap 3 bulan sekali, Mengadakan iva test setahun sekali Mengadakan operasi katarak dan operasi bibir sumbing setiap 6 bulan sekali..

\section{METODE PENELITIAN}

Jenis penelitian ini adalah kualitatif. Jenis penelitian ini dapat menggambarkan kajadian atau fenomena tertentu, mendeskripsikan dan menginterpretasikan kondisi, proses yang sedang berlangsung, akibat atau efek yang terjadi, atau tentang kecendrungan yang tengah berlangsung, berkaitan dengan kesiapan dan pelaksanaan kegiatan RSTD.

Penelitian dilakukan di RSUD Moewardi selama 5 bulan yaitu dari tahap persiapan pada bulan Juni 2019 sampai dengan tahap pelaporan hasil pada bulan September 2019

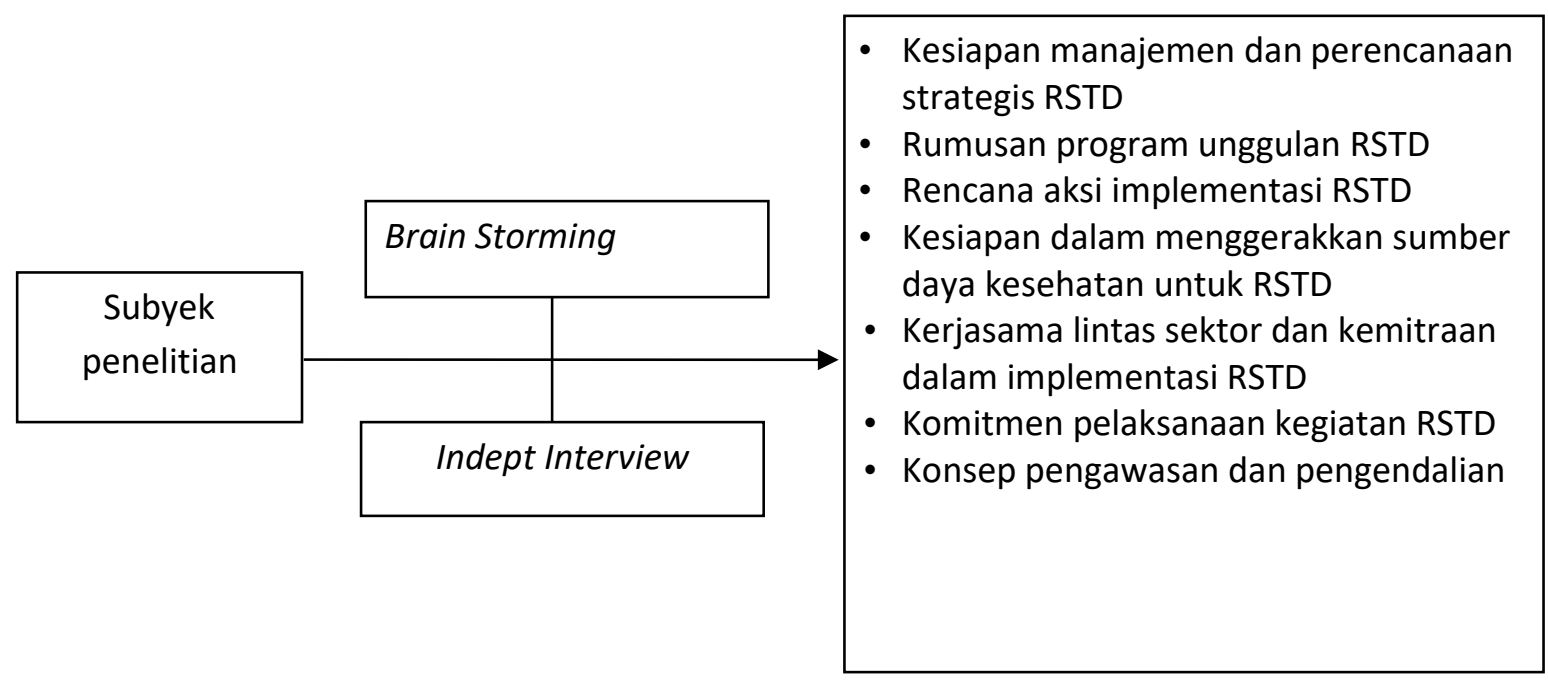

Rumah Sakit Dr Moewardi memiliki visi Rumah Sakit Terkemuka berkelas dunia,yang memiliki makna Rumah sakit Dr Moewardi harus menjadi rumah sakit terkemuka ditingkat nasional,baik dalam hal pelayanan, pendidikan, dan penelitian, dengan kulaitas yang memenuhi standar pelayanan rumah sakit tingkat dunia. Hanya dengan menjadi rumah sakit yang terkemuka dengan kelas dunia, rumah sakit Dr Moewardi akan eksis dan berkembang serta mampu menghadapi dan mengatasi tantangan /tuntunan perubahan yang semakin berat dan kompleks. (Pedoman HSR, 2014).
Struktur organisasi Rumah Sakit Tanpa dinding terdiri dariWakil Direktur UmumKabag PerencanaanKasubag Perencanaan. TIM HSR meliputi Kabid Yan Medis, kabid yan Keperawatan, Ka instansi Farmasi kasubag RT.Kegiatan yang dilaksanakan meliputi kegiatan pokok, rincian kegiatan dan pelaksanaan kegiatan.

Kegiatan Pokok,melaksanakan kegiatan promosi kesehatan seperti pengobatan gratis ,bakti sosial, di wilayah karisidenan Surakarta.

Rincian kegiatan meliputiPengobatan grtais yang dilakukan 
setiap 2 minggu sekaliMengadakan khitanan masal setiap 6 bulan sekaliMengadakan kegaitan donor darah setiap 3 bulan sekaliMengadakan iva test setahun sekali . Mengadakan operasi katarak dan operasi bibir sumbing setiap 6 bulan sekali.

\section{HASIL DAN PEMBAHASAN}

Gambaran kesiapan manajemen dan perencanaan strategis rumah sakit tanpa dinding di Rumah Sakit Moewardi Surakarta

Gambaran Kesiapan Manajemen dan Perencanaan Strategis RSTD RSUD Moewardi terkait pertanyaan ada Peraturan peraturan/ payung hukum program RSTD dari 10 responden sebagian besar $(80 \%)$ menjawab belum ada, Ada kebijakan terkait manajemen RSTD sebagian besar $90 \%$ menjawab ya, Ada kesiapan anggaran pelaksanaan RSTD sebagian besar $90 \%$ menjawab ya, Ada SDM untuk pelaksanaan program RSTD $100 \%$ menjawab ya , Ada sarana/ instrument pendukung program RSTD sebagian besar $80 \%$ menjawab ya, Ada staf RS sudah mengetahui program RSTD 80\% menjawab ya, Ada struktur organisasi RSTD, deskripsi dan spesifikasi pekerjaan, $80 \%$ menjawab ya, Ada edukasi kesehatan terhadap pasien agar sadar akan kesehatannya sebagian besar $90 \%$ menjawab ya Ada edukasi terhadap pasien untuk tatalaksana penyakitnya $100 \%$ menjawab ya, Pengelola paguyuban atau kelompok masyarakat peduli kesehatan pada program RSTD $90 \%$ menjawab ya, Ada anggaran untuk paguyuban atau kelompok masyarakat peduli kesehatan pada program RSTD

Terkait pertanyaan payung hukum yang ada di RS moewardi $80 \%$ menjawab belum ada yang ada hanya merujuk dari program unggulan gubernur jawa tengah sesuai dengan program gubernur jawa Tengah bahwa Rumah Sakit Tanpa Dinding sebagai program unggulan gubernur jawa tengah di bidang kesehatan " menjadikan masyarakat Jawa Tengah lebih sehat dan demi tercapainya visi masyarakat Jawa Tengah yang lebih sejahtera dan berdikari"

Terkait pertanyaan Ada kebijakan terkait manajemen RSTD ( $(90 \%)$ di RS moewardi sendiri sudah memiliki legalisasi,struktur organisasi dan tata kelola ,tetapi memang tidak mengistilahkan RSTD didalamnya. Melainkan program HSR-PKSR jadi yang $10 \%$ menjawab tidak karena struktur tersendiri untuk RSTD tidak ada sesuai dengan Program Rumah sakit Tanpa Dinding (RSTD) merupakan perwujudan dari upaya pemerintah daerah Provinsi Jawa Tengah guna mencapai derajat kesehatan masyarakat Jawa Tengah setinggi tingginya Program RSTD merupakan program unggulan dari Gubernur Jawa tengah dalam pelayanan kesehatan mulai promotif, rehabilitatif, kuratif, dan preventif. Pertanyaan Kebijakan terkait Kesiapan anggaran pelaksanaan RSTD untuk di RSDM $90 \%$ menjawab ya, anggaran melalui anggran SKPD RSDM 2020 belum ada, diharapkan anggaran BLU dimana saat ini tidak menentu terkait belum dibayar BPJS.sesuai Prinsip penyelenggaraan program Rumah Sakit Tanpa Dinding adalah: Kemandirian/keswadayaan yang artinya Kemampuan untuk menggunakan modal yang dimiliki mandiri atau melepaskan diri dari ketergantungan yang dimiliki oleh setiap individu, kelompok, maupun kelembagaan yang lain. SDM yang melaksanakan RSTD yang menjawab ya ada $100 \%$ Kebijakan terkait Sumber Daya Manusia untuk pelaksanaan RSTD dari tim PKRS RSDM jadi petugas khusus tidak ada tetapi menyatu dengan team PKMRS Moewardi

Sesuai Penguatan Tim Terpadu RS

Tanpa Dinding Kebijakan:a)
TersusunnyaTim terpadu pelaksana RS Tanpa Dinding internal RS; b) Kejelasan Tugas dan fungsi tim pelaksana RS Tanpa Dinding internal RS; c) Tersusunnya Tim terpadu pelaksana RS Tanpa Dinding ekternal rumah sakitd) Kejelasan Tugas dan fungsi tim pelaksana RS Tanpa Dinding ekternal RS. Bahwa untuk mendukung 
sarana / instrumen pendukung RSTD DI RS Moewardi secara khusus belum ada tetapi Sarana/instrument pendukung RSTD ada dari PKRS/HSR yang berupa Hospital Social Responsibilty. Staf yang mengetahi RSTD adalah structural dan tim PKSRHSR sedangkan ada

Kolaborasi semua tim dari perawat, fisioterappi,terapi okupasi, melaksanakan kegiatan pelayanan yang terintegrasi. Perawat memberikan pelayanan kepada masyarakat dengan on -call service, 24 jam bisa kontak langsung dengan perawat dan akan memberikan pelayanan kerumah.(Canadian Federation Of Nurses union ,2017)

Dengan pelayana ke rumah sehingga pasien merasa nyaman akan meningkatan pelayanan kesehatan sebesar 91,4 \%, memberikan pelayanan pada disability sebesar $68,8 \%$, insiden rate sebesar $10 \%$, pencegahan $56 \%$ dan kematian 7,55. Dampak yang cukup baik dalam peningkatan derajat kesehatan dengan metode home care clien.(Canadian Home care Assosiation ,2013)

Gambaran rumusan program unggulan rumah sakit tanpa dinding di Rumah Sakit Moewardi Surakarta

Terkait pertanyaan Rumusan program unggulan RSTD Ada program unggulan program RSTD 90\% menjawab ya sedangkan Ada anggaran untuk program unggulan program RSTD sebagian besar $80 \%$ menjawab ya. Gambaran rumusan program unggulan rumah sakit tanpa dinding di Rumah Sakit Moewardi Surakarta telah dilaksanakan seperti melakukan pelayanan lewat Medsos berupa Moewardi WHY dan secangkir kopi hangat, TSM dan Edukasi yang lain meliputi pengobatan gratis dan penyuluhan, seminar grtais, konsultasi via medsos. Konsultasi TV dan radio

Gambaran rencana aksi implementasi rumah sakit tanpa dinding di Rumah Sakit Moewardi Surakarta
Terkait pertanyaan Rencana Aksi Implementasi RSTD terkait pertanyaan Adakah instrumen yang akan dipakai untuk menilai tingjkat kesehatan masyarakat terhadap adanya program RSTD 100\% menjawab ya, Adakah instrumen yang akan dipakai untuk menilai kepuasan masyarakat terhadap pembinaan/ pendampingan kesehatan dari program RSTD 90\% menjawab ya, Adakah instrumen yang akan dipakai untuk menilai kesehatan pasien melalui program RSTD 90\% menjawab ya, Adakah instrumen yang akan dipakai untuk menilai kepuasan pasien terhadap layanan kesehatan dari program RSTD 100\% menjawab ya, Apakah ada rencana berupa fasilutas pelayanan informasi (hotline, dll) untuk program $90 \%$ menjawab ya, Adakah desain/ roadmap rencana aksi pelaksanaan pelayanan program RSTD 100\% menjawab ya

Gambaran rencana aksi implementasi rumah sakit tanpa dinding di Rumah Sakit Moewardi Surakarta berupa Edukasi dilakukan disetiap kegiatan Edukasi yang lain meliputi pengobatan gratis dan penyuluhan, seminar grtais, konsultasi via medsos. Konsultasi TV dan radio Setiap saat pemeriksaan oleh dokter selalu ada proses edukasi dan tata laksana penyakit.

Pelayanan kesehatan oleh perawat dalam membangun rumah sakit tanpa dinding diantaeanta melalu training curicullum for telehomecare. Program ini mampu mengidentifikasi permasalah dan tingkat kesulitan melalui telepon langsung( Sanderson D and attack L,2004).

\section{Gambaran tentang Kesiapan penggerakan sumber daya kesehatan untuk RSTD}

Kesiapan penggerakan sumber daya kesehatan untuk RSTD bahwa terkait pertanyaan Ada kesiapan institusi dalam menggerakkan sumber daya kesehatan untuk RSTD (0\% menjawab ya , Apakah kesiapan sumber daya kesehatan berasal dari semua bidang atau seksi untuk menggerakkan program RSTD90 \% 
menjawab ya, Ada sarana \& prasarana pendukung $100 \%$ menjawab ya. Gambaran tentang kesiapan dalam menggerakkan sumber daya kesehatan untuk rumah sakit tanpa dinding di Rumah Sakit Moewardi Surakarta Ada desain roadmap ,ada kesiapan institusi utk menggerakkan, ada kesiapan SDK dari semua pihak ada sarpras untuk mengerakkan SDK tapi belum disampaikan Secara rinci.

Peningkatan penduduk dan menurunnya kesehatan membutuhkan pelaynan yang lebih intensif pada pasien, CSIRO melaksanakan program yaitu rumah sakit tanpa dinding untuk memonitor keadaan pasien secara berkesinambungan, tidak hanya saat di rumah sakit tetapi observasi sampai kondisi pulih di rumah juga terpantau. (CSIRO, Australia)

Gambaran tentang kerjasama lintas sektor dan kemitraan dalam rencana implementasi rumah sakit tanpa dinding di Rumah Sakit Moewardi Surakarta

Dari 10 responden terkait pertanyaan KKerjasama lintas sektor dan kemitraan dalam rencana atau implementasi RSTD bahwa terkait pertanyaan Institusi sudah memiliki kerjasama lintas sektor dan kemitraan dengan lintas sektor $100 \%$ menjawab ya, Institusi memiliki rencana strategis dalam maping kerjasama lintas sektor $100 \%$ menjawanb ya sedangkan Adakah strategi tahapan pemberdayaan masyarakat dan kemitraan terhadap program RSTD $90 \%$ menjawab ya Gambaran tentang kerjasama lintas sektor dan kemitraan dalam rencana implementasi rumah sakit tanpa dinding di Rumah Sakit Moewardi Surakarta Institusi memiliki kerjasama dengan PEMDA, ada renstra, ada strategi pemberdayaan masyarakat tetapi belum disampaikan serta Ada paguyuban kelompok masyarakat peduli kesehatan yang meliputio club diabetes, klub lupus, klub asma, klub jantung, lansia,thalassemia dan stroke. Ada anggaran untuk paguyuban berupa fasilitasi gathering dan seminar. Belum ada anggaran unggulan RSTD, berharap anggaran dari SKPD

\section{Gambaran tentang komitmen pelaksanaan kegiatan rumah sakit tanpa dinding di Rumah Sakit Moewardi Surakarta}

Komitmen pelaksanaan kegiatan RSTD bahwa $100 \%$ responden menjawab ya berkomitmen untuk pelaksanaan RSTD. Gambaran tentang komitmen pelaksanaan kegiatan rumah sakit tanpa dinding di Rumah Sakit Moewardi Surakarta berupa Sinkronisasi program RSTD terlihat jelas dalam kegiatan HSR,PKRS,Kehumasan Dari bagian perencanaan dan humas melakukan pelayanan lewat Medsos berupa Moewardi WHY dan secangkir kopi hangat, TSM RSDM juga mempunyai daerah binaan, tujuannya untuk mendekatkan pelayanan dokter spesialis saraf kepada masyarakat

Gambaran tentang konsep pengawasan dan pengendalian rumah sakit tanpa dinding di Rumah Sakit Moewardi Surakarta

Konsep Pengawasan dan Pengendalian RSTD Ada konsep pengawasan dan pengendalian terhadap program RSTD $100 \%$ menjawab ya Ada sistem pelaporan dan umpan balik program RSTD 1005 menjawab ya, konsep penilaian jalannya sistem rujukan program RSTD menjawab ya, sinkronisasi program RSTD dengan program lainnya $100 \%$ menjawab ya Gambaran tentang konsep pengawasan dan pengendalian rumah sakit tanpa dinding di Rumah Sakit Moewardi Surakarta melalui Ada konsep pengawasan, pengendalian ada system pelaporan, system rujukan melalui SISRUT

Untuk membantu menurunkan angka kesakitan,kematian dan meningkatkan derajat kesehatan diantaranya dengan menjaga gaya hidup memalui edukasi hidup sehat, pencegahan penyakit melalui promosi kesehatan dan peningkatan perilaku kesehatan, peningkatan kemampuan perawat sangat 
mempengaruhi dan mampu memberikan motivasi dan dukungan bagi pasien (F. Zahra, 2019).Penelitian Michaell Dadd menyebutkan home monitoring sistem akan meningkatkan pelayanan secara profesional.

\section{SIMPULAN DAN SARAN}

Gambaran kesiapan manajemen dan perencanaan strategis rumah sakit tanpa dinding di Rumah Sakit Moewardi Surakarta telah disiapkan dengan baik terbukti Ada desain roadmap ,ada kesiapan institusi utk menggerakkan, ada kesiapan SDK dari semua pihak ada sarpras untuk mengerakkan SDK tapi belum disampaikan Secara rinci.

Gambaran rumusan program unggulan rumah sakit tanpa dinding di Rumah Sakit Moewardi Surakarta telah dilaksanakan seperti melakukan pelayanan lewat Medsos berupa Moewardi WHY dan secangkir kopi hangat, TSM dan Edukasi yang lain meliputi pengobatan gratis dan penyuluhan, seminar gratis, konsultasi via medsos. Konsultasi TV dan radio

Gambaran rencana aksi implementasi rumah sakit tanpa dinding di Rumah Sakit Moewardi Surakarta berupa Edukasi dilakukan disetiap kegiatan Edukasi yang lain meliputi pengobatan gratis dan penyuluhan, seminar grtais, konsultasi via medsos. Konsultasi TV dan radio Setiap saat pemeriksaan oleh dokter selalu ada proses edukasi dan tata laksana penyakit.

Gambaran tentang kesiapan dalam menggerakkan sumber daya kesehatan untuk rumah sakit tanpa dinding di Rumah Sakit Moewardi Surakarta Ada desain roadmap ,ada kesiapan institusi utk menggerakkan, ada kesiapan SDK dari semua pihak ada sarpras untuk mengerakkan SDK

Gambaran tentang kerjasama lintas sektor dan kemitraan dalam rencana implementasi rumah sakit tanpa dinding di Rumah Sakit Moewardi Surakarta Institusi memiliki kerjasama dengan PEMDA, ada renstra, ada strategi pemberdayaan masyarakat disampaikan serta Ada paguyuban kelompok masyarakat peduli kesehatan yang meliputio club diabetes, klub lupus, klub asma, klub jantung, lansia,thalassemia dan stroke. Ada anggaran untuk paguyuban berupa fasilitasi gathering dan seminar. Belum ada anggaran unggulan RSTD, berharap anggaran dari SKPD

Gambaran tentang komitmen pelaksanaan kegiatan rumah sakit tanpa dinding di Rumah Sakit Moewardi Surakarta berupa Sinkronisasi program RSTD terlihat jelas dalam kegiatan HSR,PKRS,Kehumasan Dari bagian perencanaan dan humas melakukan pelayanan lewat Medsos berupa Moewardi WHY dan secangkir kopi hangat, TSM RSDM juga mempunyai daerah binaan , tujuannya untuk mendekatkan pelayanan dokter spesialis saraf kepada masyarakat

Gambaran tentang konsep pengawasan dan pengendalian rumah sakit tanpa dinding di Rumah Sakit Moewardi Surakarta melalui Ada konsep pengawasan, pengendalian ada system pelaporan, system rujukan melalui SISRUT.

\section{DAFTAR PUSTAKA}

1. Canadian Home Care assosiation ,2016 )Afirst step toward additional and improved home care services forr all Canadian.

2. Canadian Home Care asssosiation (2013). Portraits of home care in canadian, Missisiagua, author.

3. Duncan sanderson and Lynda attack (2004).Teaching Nurses to build a hospital without wall,developing a Training Curicullum for Telehomecare.

4. Jonh M Burt (2013) Hospital whithout wall, Departemen of Health and safety,Western kentucky University.

5. LS Wilson et all(2000), building the hospital Without wall -CSIRO, Australia 
6. Michaell Dadd, et all (2002) Lesson learned From the Hospital Whitout wall Project

7. Zahra Varsi,(2019) Hospital without wall,The Future of the nursing profession in Iran
8. Michaell Dadd, et all (2002) Lesson learned From the Hospital Whitout wall Project.

9. Pedoman Hospital social responsibilty (2014),RSDM 